\title{
Coaching and guidance with patient decision aids: A review of theoretical and empirical evidence
}

Dawn Stacey ${ }^{1 *}$, Jennifer Kryworuchko², Jeff Belkora ${ }^{3}$, B Joyce Davison ${ }^{4}$, Marie-Anne Durand ${ }^{5}$, Karen B Eden ${ }^{6}$, Aubri S Hoffman ${ }^{7}$, Mirjam Koerner ${ }^{8}$, France Légaré ${ }^{9}$, Marie-Chantal Loiselle ${ }^{10}$, Richard L Street Jr $r^{11}$

From The International Patient Decision Aid Standards (IPDAS) Collaboration s Quality Dimensions: Theoretical Rationales, Current Evidence, and Emerging Issues

Rockville, MD, USA. 13 September 2012

\begin{abstract}
Background: Coaching and guidance are structured approaches that can be used within or alongside patient decision aids (PtDAs) to facilitate the process of decision making. Coaching is provided by an individual, and guidance is embedded within the decision support materials. The purpose of this paper is to: a) present updated definitions of the concepts "coaching" and "guidance"; b) present an updated summary of current theoretical and empirical insights into the roles played by coaching/guidance in the context of PtDAs; and c) highlight emerging issues and research opportunities in this aspect of PtDA design.

Methods: We identified literature published since 2003 on shared decision making theoretical frameworks inclusive of coaching or guidance. We also conducted a sub-analysis of randomized controlled trials included in the 2011 Cochrane Collaboration Review of PtDAs with search results updated to December 2010. The sub-analysis was conducted on the characteristics of coaching and/or guidance included in any trial of PtDAs and trials that allowed the impact of coaching and/or guidance with PtDA to be compared to another intervention or usual care.

Results: Theoretical evidence continues to justify the use of coaching and/or guidance to better support patients in the process of thinking about a decision and in communicating their values/preferences with others. In 98 randomized controlled trials of PtDAs, 11 trials (11.2\%) included coaching and 63 trials (64.3\%) provided guidance. Compared to usual care, coaching provided alongside a PtDA improved knowledge and decreased mean costs. The impact on some other outcomes (e.g., participation in decision making, satisfaction, option chosen) was more variable, with some trials showing positive effects and other trials reporting no differences. For values-choice agreement, decisional conflict, adherence, and anxiety there were no differences between groups. None of these outcomes were worse when patients were exposed to decision coaching alongside a PtDA. No trials evaluated the effect of guidance provided within PtDAs.

Conclusions: Theoretical evidence continues to justify the use of coaching and/or guidance to better support patients to participate in decision making. However, there are few randomized controlled trials that have compared the effectiveness of coaching used alongside PtDAs to PtDAs without coaching, and no trials have compared the PtDAs with guidance to those without guidance.
\end{abstract}

\footnotetext{
* Correspondence: dstacey@uottawa.ca

${ }^{1}$ School of Nursing, University of Ottawa and Clinical Epidemiology Program, Ottawa Hospital Research Institute, 451 Smyth Road (RGN Room 1118), Ottawa, Ontario, K1H 8M5, Canada

Full list of author information is available at the end of the article
} 


\section{Background}

Coaching and guidance are structured approaches that can be used within or alongside patient decision aids (PtDAs). Both approaches are designed to help patients think about their options in preparation for discussing the decision with their practitioner(s). Underlying these concepts is the assumption that the process of decision making requires cognitive activities to understand options and their attributes, as well as two-way communication between the patient and his/her practitioner(s) to verify understanding of the options and clarify patients' informed preferences. This decision-making process may also include significant others involved in the decision.

Coaching and guidance are important concepts in the field of PtDA design and development. In 2005, the International Patient Decision Aid Standards (IPDAS) Collaboration developed a set of evaluative criteria for assessing the quality of PtDAs [1]. As part of this process, the IPDAS Collaboration: a) identified coaching/ guidance in deliberation and communication as one of twelve broad dimensions of PtDA design; b) proposed specific evaluative criteria for each of these twelve dimensions, including evaluative criteria for PtDA-based coaching/guidance; and c) invited consensus voters to indicate, within each dimension, the importance of each evaluative criterion. To help the consensus voters, the IPDAS Collaboration provided them with a twelve-chapter "background document" with information about the definitional, theoretical, and evidentiary background for each of the twelve dimensions, including a chapter specific to guidance and coaching [2]. One result of the consensus process was that the three evaluative criteria that focused on guidance (i.e., "PtDA provides a stepby-step way to make a decision"; "PtDA suggests ways to talk about the decision with practitioners"; and PtDA includes tools like worksheets or lists of questions to use when discussing options with a practitioner") were considered highly important, in that each criterion was rated 8 out of 9 on an importance scale. Another result of the consensus process was that the two criteria that focused on coaching (i.e., "PtDA offers option of working with a trained coach to help patients consider the options" and "PtDA prepares one to talk about the decision with a practitioner") were considered moderately important, in that both were rated 5 out of 9 [1].

The purpose of this paper is to move beyond the IPDAS Collaboration's 2005 "background document" by: a) presenting updated definitions of the concepts coaching and guidance; b) presenting an updated summary of current theoretical and empirical insights into the roles played by coaching/guidance in the context of PtDAs; and c) highlighting emerging issues and research opportunities in this aspect of PtDA design.

\section{Coaching and guidance: definitions}

Coaching is defined as the provision of support by a trained individual (either in person or remotely-for example by telephone or Internet), who is supportive but non-directive, for a patient or family facing a decision [3]. Using an iterative verbal exchange, elements of coaching include: a) assessing the patients' decision-making needs; b) providing information on their options, benefits, and harms (e.g., verbally or with patient education resources such as PtDAs); c) verifying their understanding; d) clarifying their values associated with the attributes of the options, and their attitude toward risks; e) building their skills in deliberating, communicating, and accessing support; f) screening for barriers to implementation; and $g$ ) facilitating progress in decision making [4]. Although the patient may express their leaning toward a specific option to the decision coach, agreeing upon an option occurs during consultation with the practitioner rather than with the coach. Trained health professionals, students, or laypeople can provide coaching before and/or after using a PtDA, as part of its delivery, or in the absence of PtDAs. Coaching may also be referred to as decision support, counselling, navigation, and/or facilitation of the decision-making processes.

Guidance is defined as an explicit element embedded within the decision support materials that can facilitate a self-directed approach to the process of decision making. It can be included within the PtDA or as a resource used alongside the PtDA. Examples of elements used to provide guidance include: a) a list of steps or systematic approach for making a decision; b) a worksheet to help patients to clarify their values associated with the options' attributes that can be shared with their practitioner; c) a list of questions and/or an invitation for users to identify questions to ask the practitioner (or decision coach); and/or d) an automated summary of the patients' priorities and decisional needs (e.g., their knowledge, values, preference, the results of decision analysis) that can be given to the patient and shared with the practitioner(s), decision coach, and/or significant others involved in the decision.

\section{Theoretical justification}

There are several rationales informing the use of coaching and guidance within or alongside PtDAs, some of which are from current or emerging decision-making theories or conceptual models [5]. In this section, we summarize the theoretical underpinnings of coaching and guidance from the IPDAS Collaboration's original 2005 "background document" [2], and add new theoretical rationale that we identified.

\section{Achieving higher quality decisions}

The objective of patient-oriented decision support is to help patients make higher quality decisions that are 
informed with the best available evidence and that reflect the patients' values for the options' attributes $[6,7]$. The main hypothesis underlying the use of guidance and coaching within or alongside PtDAs is that:

a) since patients are better able to participate in making decisions about their healthcare and to achieve a higher quality decision if they are supported in the process of thinking about a decision and discussing it with others,

and

b) since coaching and guidance may provide that support, by improving patients' deliberation and communication skills, improving follow-through on a chosen option, and managing patients' emotional distress,

then

c) coaching and guidance may help patients make higher quality decisions. See Table 1.

\section{Avoiding decision pitfalls}

Patients and practitioners do not naturally follow the axioms of normative decision theory [8-10], but, when inconsistencies are highlighted, many willingly change their choices to be more aligned with these principles. Thus, explicit guidance or decision coaching in the steps of deliberation can overcome some of the common decision-making pitfalls.

Improving the quality of patient-provider communication Two-way communication is essential for shared decision making, but does not guarantee that shared decision making has occurred [11,12]. Two-way communication using high quality content (e.g., the provision and comprehension of evidence-based information, and the acknowledgment of individual values and preferences), coupled with strong patient-provider relationships, has been linked to greater satisfaction and positive health outcomes. Alternatively, poor communication has been linked to dissatisfaction, conflict, and worse outcomes [13]. Studies have documented the poor quality of communication between patients and providers $[14,15]$. Examples of poor communication include: a) one-way communication in which the physician dominates the discussion; b) a focus limited to medical facts, not thoughts/feelings or values associated with the options' attributes; and c) documentation using a traditional problem-oriented note that does not incorporate elements of two-way communication or shared decision making [16]. Therefore, patients and practitioners may benefit from coaching and/or guidance to foster higher quality two-way communication.

\section{Enhancing learning}

Consistent with principles of adult learning, patients learn in different ways [17-19]. Some patients prefer to learn from others, some prefer written, video, or interactive materials, and some prefer more than one approach to learning. Many researchers argue that learning and skill acquisition happen most effectively when patients are engaged in the process-often with the support of a coach-rather than by simply receiving factual information $[17,20]$. Patients are more apt to learn when messages and information are tailored to their situation, their needs, and their concerns $[17,18,21]$.

\section{Managing emotional distress}

A new diagnosis can cause significant emotional distress that often disrupts coping and problem-solving skills [22]. Although psychosocial services can help address

Table 1 Theoretical Rationale that Coaching and Guidance can Improve Decision Quality

\begin{tabular}{|c|c|}
\hline By. & Coaching / Guidance can... \\
\hline $\begin{array}{c}\text { Increasing critical reflection, anticipating and avoiding common pitfalls (e.g., anchoring, } \\
\text { misconceptions, etc.) that can undermine effective decision making; } \\
\text { Taking someone through the steps of decision making; } \\
\text { Helping patients become more informed by providing information, tailoring information, } \\
\text { brainstorming and answering questions, stimulating patients to ask questions, and/or verifying } \\
\text { understanding; } \\
\text { Clarifying patients' values by facilitating reflection, completing values clarification exercises, and/or } \\
\text { sharing others' experiences; } \\
\text { and/or } \\
\text { Building self-efficacy in decision making }\end{array}$ & Improve patients' deliberation skills. \\
\hline $\begin{array}{c}\text { Helping patients prepare questions and identify concerns; } \\
\text { Teaching skills for raising difficult subjects; } \\
\text { Facilitating patients' communicative capacity in the process of decision making; and/or } \\
\text { Providing a worksheet or list of questions to share with the practitioner }\end{array}$ & $\begin{array}{c}\text { Enhance patients' skills in communicating } \\
\text { with their practitioner(s). }\end{array}$ \\
\hline Helping patients to anticipate and overcome barriers to implementing the desired option & $\begin{array}{c}\text { Improve follow-through on the chosen } \\
\text { option. }\end{array}$ \\
\hline $\begin{array}{l}\text { Helping patients to improve their ability to use coping skills; } \\
\text { and/or } \\
\text { Helping patients to enhance their problem-solving skills }\end{array}$ & Reduce patients' emotional distress. \\
\hline
\end{tabular}


excessive emotional distress, emotions are often important in personal decision making before, during, and after the decision [23]. First, emotions may propel the patient to deliberate and to act in support of or in opposition to an option. Second, emotions may give the patient positive or negative feedback. For example, during the decision process the patient may start to feel anxiety or fear about what is going to happen and may start anticipating decision regret. Decisional conflict is another type of emotional arousal that commonly occurs in patients making health decisions. It is defined as uncertainty about which course of action to take when choosing among actions that involve risk, loss, regret, or challenge to personal life values [24]. Some emotional arousal appears to be necessary to stimulate patients' desire and capability to participate effectively in decision making [25]. The individualized approach used in coaching may improve the likelihood that patients' emotions are considered throughout the decision-making process, particularly when clarifying the importance of attributes of options and acknowledging patients' concerns.

\section{Decision making conceptual models that inform decision coaching}

The Interprofessional Shared Decision Making Model, the Framework for Decision Coach Mediated Shared Decision Making, and the FAST model of critical reflection (defined below) have been used to inform the role of decision coaching provided alongside PtDAs (see Table 2) [3,26-29].

The Interprofessional Shared Decision Making Model (IP-SDM Model) assumes that two or more healthcare professionals collaborate to achieve shared decision making with the patient either concurrently or sequentially; one of these professionals may undertake the decision coaching role. According to this model, the decision coach is a trained health professional. The interprofessional team members, including the decision coach, may have varying levels of involvement at different steps of the decisionmaking process, but overall they share a common understanding of this process (from deliberation to implementation of the chosen option). The IP-SDM model has been validated in primary care and home care clinical environments [28,30], and shown to be relevant in research studies evaluating patients' decision making needs in the intensive care unit and renal dialysis decision making [31,32].

The Framework for Decision Coach Mediated Shared Decision Making expands the traditional patient-practitioner dyad to include the role of decision coaching, and integrates the Ottawa Decision Support Framework interventions as the key elements in the coaching role [3,33]. The Framework for Decision Coach Mediated Shared Decision Making assumes that higher quality decisions are achieved when patients and practitioners participate in decision making and a decision coach facilitates patient engagement in this process. The Ottawa Personal Decision Guide is a generic PtDA consistent with this framework that can be used to facilitate the provision of decision coaching with patients. Compared to controls, health professionals who were trained in decision coaching using PtDAs were more likely to assess patients' decisional needs, discuss values associated with their options, and assess for support needed from others involved in the decision [34-36].

The FAST (Formulate issues, Analyze issues, $\underline{\text { Synthe- }}$ size insights, Translate insights into action) model of critical reflection informed the decision coaching role as part of the process of PtDA implementation [26,37-40]. The coaching role in this program was designed to improve patient participation in consultations with their practitioner. Decision coaches include post-baccalaureate premedical students, nurses, and psychologists. Compared to usual care, men with prostate cancer randomized to the coaching intervention based on FAST had higher decision self-efficacy and lower decisional regret [40]. Another randomized controlled trial found that telephone delivery of coaching using the FAST model was as effective as in-person delivery of coaching, both producing pre/post improvements in decision selfefficacy [41].

Decision making conceptual models that inform guidance Decision making conceptual models that inform guidance for patients' healthcare decision making are limited, to the best of our knowledge, to the Ottawa Decision Support Framework, which explicitly includes the element of guidance (see Table 2) [33]. This framework asserts that participants' (e.g., individual, couple, family, practitioner) decisional needs will affect the achievement of a higher quality decision, which, in turn, affects actions or behaviours (e.g., delay), health outcomes, emotions (e.g., regret, blame), and appropriate use of health services $[33,42]$. Decision support interventions based on this framework are designed to address modifiable decisional needs. Guidance is one example of an explicit element included in decision support intervention (e.g., guiding clients to consider which benefits and harms are most important to them). The Ottawa Decision Support Framework has been commonly used a) for developing PtDAs for numerous decisions in Canada, Australia, the United States, Japan, and the United Kingdom [5,43], and b) for training healthcare professionals [44].

\section{Empirical evidence from studies of PtDAs}

The following evidence summary for coaching/guidance is based on findings from the Cochrane Collaboration Review of PtDAs, which included randomized controlled trials published to the end of $2009(\mathrm{~N}=86)$ [43], as well 
Table 2 Decision Making Conceptual Models to Inform Decision Coaching and/or Guidance

\begin{tabular}{|c|c|c|c|c|}
\hline $\begin{array}{l}\text { Conceptual } \\
\text { Model }\end{array}$ & Goal & Provided by & SDM /Coaching or Guidance Process & Implemented and/or evaluated in \\
\hline $\begin{array}{l}\text { IP-SDM Model } \\
\text { (coaching) }\end{array}$ & $\begin{array}{l}\text { To assist two or more } \\
\text { health professionals to } \\
\text { achieve shared decision } \\
\text { making with the patient }\end{array}$ & $\begin{array}{l}\text { Health professional } \\
\text { trained to support } \\
\text { the patient's } \\
\text { involvement in } \\
\text { SDM }\end{array}$ & $\begin{array}{l}\text { 1) Making explicit that a decision needs } \\
\text { to be made, 2) Exchanging information } \\
\text { (including the use of PtDAs), 3) } \\
\text { Clarifying values/preferences, 4) } \\
\text { Determining feasibility of options, 5) } \\
\text { Reaching a choice, and 6) Implementing } \\
\text { the chosen option. }\end{array}$ & $\begin{array}{c}\text { Primary care (CA, US); Intensive care } \\
\text { (CA, US); Nephrology (CA); Homecare } \\
\text { (CA) }\end{array}$ \\
\hline $\begin{array}{l}\text { Framework for } \\
\text { Decision Coach } \\
\text { Mediated SDM } \\
\text { (coaching) }\end{array}$ & $\begin{array}{l}\text { To achieve higher quality } \\
\text { decisions }\end{array}$ & Health professional & $\begin{array}{l}\text { a) Assessing patients' decisional conflict } \\
\text { and related modifiable deficits in } \\
\text { knowledge, values clarity and support; } \\
\text { b) Tailoring decision support to meet } \\
\text { patients' needs by facilitating access to } \\
\text { PtDAs and/or providing evidence-based } \\
\text { information, verifying understanding, } \\
\text { clarifying values, building skills in } \\
\text { deliberation, communication and } \\
\text { accessing support; c) Monitoring and } \\
\text { facilitating patients' progress in decision } \\
\text { making; and d) Screening for factors } \\
\text { influencing decision implementation, } \\
\text { including patients' motivation and self- } \\
\text { efficacy, and other potential barriers } \\
\text { impeding implementation. }\end{array}$ & $\begin{array}{c}\text { Primary care call centre (CA, US, Chile); } \\
\text { Cancer care (AU, UK, Japan); End of life } \\
\text { care (CA); Various decisions in training } \\
\text { of graduate students (CA) }\end{array}$ \\
\hline $\begin{array}{c}\text { FAST } \\
\text { (coaching) }\end{array}$ & $\begin{array}{l}\text { To improve participation } \\
\text { in specialty or chronic } \\
\text { care consultations }\end{array}$ & $\begin{array}{l}\text { Students/trainees, } \\
\text { peer navigators, } \\
\text { allied health } \\
\text { professionals }\end{array}$ & $\begin{array}{l}\text { To help patients after they have } \\
\text { reviewed a PtDA (or education materials } \\
\text { in the absence of a PtDA) to formulate } \\
\text { issues that they will subsequently } \\
\text { analyze with their practitioner(s). }\end{array}$ & $\begin{array}{l}\text { Orthopaedics (US, UK); Chronic care, } \\
\text { (US, UK); Cancer care (US, UK) }\end{array}$ \\
\hline $\begin{array}{l}\text { Ottawa } \\
\text { Decision } \\
\text { Support } \\
\text { Framework } \\
\text { (guidance) }\end{array}$ & $\begin{array}{l}\text { To address modifiable } \\
\text { decisional needs } \\
\text { contributing to decisional } \\
\text { conflict }\end{array}$ & $\begin{array}{l}\text { Incorporated as } \\
\text { steps in PtDAs }\end{array}$ & $\begin{array}{c}\text { Structures the process of decision } \\
\text { making by making explicit a set of steps } \\
\text { and encouraging patients to } \\
\text { communicate their informed preferences } \\
\text { with others involved in the decision (e. } \\
\text { g., practitioner, family, friends) }\end{array}$ & $\begin{array}{c}\text { Large variety of decisions (AU, CA, US, } \\
\text { Japan, UK) }\end{array}$ \\
\hline
\end{tabular}

$\mathrm{AU}=$ Australia; $\mathrm{CA}=$ Canada; US = United States; UK = United Kingdom; SDM = shared decision making

as from an updated search of PtDA trials published to the end of $2010(\mathrm{~N}=12)$. For decision coaching, we also used a sub-analysis of trials that evaluated decision coaching within trials of PtDAs [4]. This sub-analysis a) included trials that allowed the impact of decision coaching provided by a healthcare professional to be compared to another intervention and/or usual care, and $b$ ) excluded trials in which patients were exposed to coaching in both arms of the trial [45-48]. One other trial was excluded because only 12 of 136 women (8.8\%) in the intervention group were exposed to decision coaching [49]. In this single study in which decision coaching was optional, few women initiated contact with the coach or accepted coach-initiated contact. These authors surmised that women in this study may have opted out of coaching because they did not perceive, prospectively, any added value compared to just using the decision guide [49].

\section{Evidence about decision coaching}

Of 98 trials of PtDAs, 11 (11.2\%) included decision coaching provided by nurses, genetic counsellors, pharmacist, physicians (who were not the primary practitioner for the patient), psychologists, or health educators. Table 3 summarizes the findings from trials that evaluated decision coaching. A PtDA plus decision coaching compared to usual care improved knowledge and decreased mean costs [4]. Compared to baseline, both coaching alone and the PtDA alone improved knowledge, but there was no statistically significant difference in knowledge between groups. The impact of comparisons on other outcomes was more variable, with some trials showing positive effects (e.g., participation in decision making, satisfaction, actual choice) and other trials reporting no differences (e.g., participation in decision making, satisfaction, actual choice, values-choice agreement, decisional conflict, adherence, anxiety). Overall, none of these outcomes were worse when patients were exposed to decision coaching.

\section{Evidence about guidance}

Among 98 randomized controlled trials, 63 (64.3\%) used PtDAs that contained some sort of explicit guidance in deliberation and/or communication. Examples of PtDAs 
Table 3 Summary of Findings for Decision Coaching ("n" = number of studies)

\begin{tabular}{|c|c|c|c|}
\hline & Positive Results $(p<0.05)$ & Mixed Results & No Difference \\
\hline $\begin{array}{l}\text { Coaching plus a PtDA } \\
\text { versus Usual Care } \\
\qquad(n=5)\end{array}$ & $\begin{array}{c}\text { - Improved knowledge [69-71] } \\
\text { - Decreased mean costs [71,72] } \\
\text { - Fewer physical limitations to } \\
\text { lifestyle activities [72] } \\
\text { - Decreased hysterectomies for } \\
\text { more conservative options [72] } \\
\text { - Increased psycho-education } \\
\text { rather than medication for } \\
\text { schizophrenia [69] } \\
\text { - Increased single embryo } \\
\text { transfers compared to double } \\
\text { embryo transfer [71] }\end{array}$ & 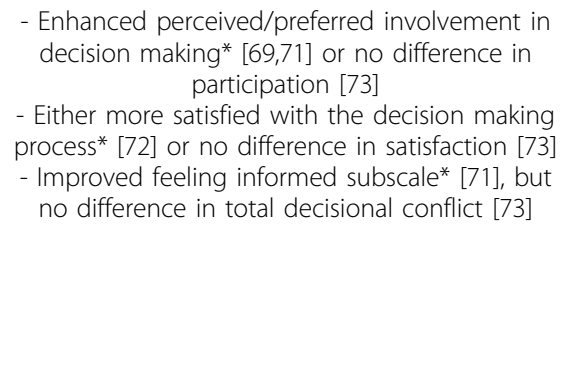 & $\begin{array}{c}\text { - Values-choice agreement [70] } \\
\text { - Satisfaction-uncertainty and control } \\
\text { levels }[71] \\
\text { - Anxiety or depression }[71] \\
\text { - Uptake of genetic testing }[70,73]\end{array}$ \\
\hline $\begin{array}{l}\text { Coaching versus } \\
\text { PtDA }(n=4)\end{array}$ & $\begin{array}{c}\text { - Increased values-choice } \\
\text { agreement [74] } \\
\text { - Similar improvements in } \\
\text { knowledge [74-77] } \\
\text { - Increased satisfaction with the } \\
\text { decision making process [77] }\end{array}$ & $\begin{array}{l}\text { - Decreased decisional conflict* }[74] \text { or no } \\
\text { difference }[75,77]\end{array}$ & $\begin{array}{l}\text { - Participation [75] } \\
\text { - Preparation for decision making [75] } \\
\text { - Use of hormones for menopause } \\
\text { [74,75] or uptake of prenatal } \\
\quad \text { screening [77] } \\
\text { - Adherence to hormones for } \\
\quad \text { menopause }[74,75] \\
\text { - Anxiety or pregnancy outcomes [77] }\end{array}$ \\
\hline $\begin{array}{l}\text { Coaching plus a PtDA } \\
\text { versus PtDA Alone } \\
(n=4)\end{array}$ & $\begin{array}{l}\text { - Increased participation in } \\
\text { decision making [78] } \\
\text { - Decreased mean costs [72] } \\
\text { - Similar improvements in } \\
\text { knowledge [70] }\end{array}$ & & $\begin{array}{l}\text { - Values-choice agreement [70] } \\
\text { - Satisfaction with the decision } \\
\text { making process [72] } \\
\text { - Uptake of hysterectomy [72], } \\
\text { genetic testing [70], or prostate } \\
\text { cancer screening [79]; } \\
\text { - Health outcomes [72], anxiety or } \\
\text { depression [78] }\end{array}$ \\
\hline
\end{tabular}

that did not provide explicit guidance used simple paper-based consent formats [50,51] or computer-based programs with conjoint analysis [52]. The amount of guidance varied considerably. Table 4 summarizes the types of guidance provided (these are not mutually exclusive). Only one trial of PtDAs compared guidance provided by different individuals [43]. In this trial, findings revealed that, compared to the same PtDA administered by a research assistant prior to the consultation, a PtDA administered by the physician during the consultation showed a non-statistically significant trend of higher acceptability of the PtDA and lower decisional conflict [53]. Given that more detailed PtDAs are more likely to include one or more of these elements of guidance in deliberation or communication, we also report evidence comparing simple to detailed PtDAs. Compared to simpler PtDAs, more detailed PtDAs produced higher gains in knowledge, more realistic expectations, and a greater match between patients' values and their chosen option [43]. However, the link between detailed PtDAs, explicit guidance, and effectiveness needs to be tested empirically.

\section{Discussion}

Our review of coaching and guidance focused on studies satisfying the inclusion criteria from the 2011 Cochrane Review of Patient Decision Aids. Our findings revealed that theoretical evidence continues to justify the use of coaching and/or guidance to better support patients to participate in decision making. However, there are few randomized controlled trials that have compared the effectiveness of coaching used alongside PtDAs to PtDAs without coaching, and no trials have compared the PtDAs with guidance to those without guidance. Below, we discuss these observations in more detail.

\section{Our findings about guidance}

As noted above, we found no known randomized trials that have isolated and measured the effect of guidance in PtDAs and/or of summary tools used to inform the decision making process within the patient-practitioner consultation. Therefore, research is required to determine the contribution of guidance within PtDAs or used alongside PtDAs. Research is underway to better understand the constructs of automated guidance within technologybased decision support systems.

\section{Our findings about decision coaching}

We were interested in comparing our findings from a systematic review of PtDAs that included studies of coaching alongside PtDAs to findings from other systematic reviews that did not include PtDAs. Therefore, we identified systematic reviews that included coaching as part of an intervention to enhance the quality of patient-physician communication [54,55].

One systematic review included coaching interventions such as engaging the patient in discussion of the problem, 
Table 4 Types and Frequency of Guidance Provided within PtDAs

\begin{tabular}{|c|c|}
\hline Type of Guidance & $\begin{array}{l}\text { Frequency of occurrence in } \\
\text { published studies }\end{array}$ \\
\hline Step-by-step process for making the decision & 27 \\
\hline Worksheet with questions relevant to the decision-making process & 31 \\
\hline $\begin{array}{l}\text { Administered by the physician in the consultation or by a research assistant (e.g., decision boards, decision } \\
\text { cards, or computer program) }\end{array}$ & 9 \\
\hline $\begin{array}{c}\begin{array}{c}\text { Explicitly tells patients to communicate with their practitioners by asking questions and sharing their } \\
\text { preferences }\end{array} \\
\end{array}$ & 7 \\
\hline $\begin{array}{c}\text { Interactive computer programs: inherently guided the patient through the PtDA and decision-making } \\
\text { process }\end{array}$ & 6 \\
\hline $\begin{array}{c}\text { Summaries that could be shared with the practitioner(s) during the consultation (e.g., completed } \\
\text { worksheets/workbook, computer printout indicating treatment preferences, letter with results of decision } \\
\text { analysis) }\end{array}$ & 42 \\
\hline
\end{tabular}

For more information, see "Table of Characteristics of Included Studies" in the Cochrane Collaboration Review of Patient Decision Aids [43]

encouraging questions and participation in decision making about management, as well as discussion of emotions and feelings [54]. These interventions produced positive psychological outcomes in 26 of 35 trials (e.g., reduced anxiety and depression, enhanced quality of life, and wellbeing) and positive physical outcomes in 11 of 25 trials (e.g., reduced pain and improved functional status). Interestingly, PtDA studies with or without coaching focused more on educational and decision-related proximal outcomes than on psychological outcomes. Generally, PtDA studies have included some secondary psychological measures, such as anxiety, and found no difference. This is sometimes interpreted along the lines of "decision support does not psychologically harm patients", which would presumably be occurring if it increased anxiety [43]. However, broader literature on coaching (outside of PtDAs) suggests psychological benefits such as reductions in anxiety [54]. Further research is needed to understand the impact of coaching delivered with PtDAs on psychological outcomes.

Another systematic review of interventions directed at enhancing patients' participation in the consultation included interventions such as coaching that focused on question-asking, raising concerns, and requesting clarification or checking understanding [55]. Of 16 trials, 10 reported significant increases in patient participation in the consultation and 5 had nonsignificant increases. Furthermore, patients who had greater participation also experienced more sense of control and preferred to be more active in the consultation. These results suggest that coaching outside of the PtDA context produces similar benefits as those we found in our review for patient participation.

Although our findings indicated that coaching improved patients' knowledge and showed no detrimental effect on other patient outcomes, little detail was reported on the "dose" of coaching used in these trials. And, in fact, in the single trial in which patients were given the option of coaching, few took advantage of this intervention [49].

Our findings also lack detail on population or systemlevel outcomes. A randomized controlled trial featuring coaching and PtDAs provides insight into the influence of coaching when implemented at a large scale with members of a health insurance plan [56]. This trial involved 174,120 individuals with selected medical conditions, and featured telephone-based coaching on topics such as shared decision making, self-care, and behavioural change [56]. Individuals were assigned to one of two groups, which were then randomized to usual versus enhanced outreach. Compared to usual outreach, the enhanced outreach group had lower cut points for offering coaching to individuals, based on their predicted future costs and health conditions, and these individuals received more outreach calls (five versus three calls). Findings revealed that patients in the enhanced outreach group were more likely to receive coaching (22.2\% versus $6.3 \%)$ and be sent a PtDA (41.1 versus 11.4 per thousand per year) for preference-sensitive conditions that put them at risk for a surgical intervention (e.g., lumbar surgery, knee/hip replacement, cardiac revascularization, prostatectomy, hysterectomy). Consistent with findings from the Cochrane Review of Patient Decision Aids [43], the authors report that "the number of surgical procedures performed for the six targeted preference-sensitive conditions in either the inpatient or outpatient setting was $9.8 \%$ lower in the enhanced-support group than in the usual-support group $(p=0.04)$ ". This finding is interesting, in that it suggests that expanding the reach of coaching reduces healthcare resource utilization under pragmatic, largescale conditions.

Implications for research, policy, and practice

Several implications for research, policy, and practice have been highlighted by our updated review of the 
definitional, theoretical, and evidentiary basis for using coaching and guidance within or alongside PtDAs. We discuss these implications in the following text.

\section{Clarifying the concepts}

The original definitions for coaching and guidance that had been written for the IPDAS Collaboration's 2005 "background document" were primarily based on concepts of health coaching $[57,58]$ and communication processes [59-62]. Compared with those earlier attempts, we have provided more explicit definitions, in order to simplify how we communicate about those two major concepts. To update the definition of "coaching" (see Coaching and guidance: definitions - coaching), we removed the term "balanced instruction", replacing it with "non-directive support". As well, more details on the elements of coaching were added in order to be consistent with more recent literature on decision coaching $[3,4,28,63,64]$. To update the definition of "guidance" (see Coaching and guidance: definitions Guidance), we created a more succinct definition and added the automated summary of the patients' decisional information that is used in some clinical settings and that is available as a print-out for some online PtDAs $[65,66]$.

Conceptual clarity has been somewhat impaired with the emergence of telephone menus or e-tools often called automated decision coaching [63]; however, human interaction is not involved and therefore it fits with our definition of guidance rather than coaching. To further enhance conceptual clarity for coaching and guidance, a concept analysis should be conducted.

\section{New theoretical frameworks inclusive of coaching}

Since the coaching and guidance chapter was written for the original 2005 IPDAS "background document", there has been a theory analysis of existing shared decision making conceptual models [29], and several newer models have appeared in the literature that make explicit the role of coaching [3,26-28]. With renewed attention to coaching, barriers interfering with the delivery of decision coaching in routine clinical practice are important to consider. Examples of barriers include: a) lack of awareness, knowledge, and skills in decision coaching among health professionals; b) inadequate decision coach training; c) lack of time in clinical practice interfering with developing and using decision coaching skills; and d) inadequate environmental supports to facilitate the decision coach role $[38,64,67]$.

Therefore, in order to better address barriers, it seems that the theoretical models underpinning decision coaching interventions need to be incorporated into broader conceptual frameworks about implementation. To date, theoretical work has contributed to understanding the components of interventions (PtDAs, coaching, and/or guidance) that produce outcomes; however, to better understand the potential for broader implementation of SDM approaches, next steps include gaining an understanding of: 1) the mechanisms or reasons why the interventions have the effects that they do; and 2) the ways in which the elements of context influence these mechanisms. For example, if coaching works because people feel empowered as legitimate decision makers, then such an intervention might be most effective in a policy environment that promoted patient involvement, but be least effective in an environment that reinforced the need to have physician agreement with the decision (an aspect of physician power). Using conceptual frameworks or theories to guide studies of coaching or guidance with PtDAs is essential to understanding how such interventions have impact.

Lack of empirical evidence to support coaching or guidance with PtDAs

More evaluative investigation is required to understand: a) the added effect of decision coaching beyond the PtDA; b) which population(s) could most benefit from decision coaching; c) who should deliver this intervention-a health professional or lay coaches; d) the effect of a coaching intervention that is tailored to the unique factors influencing patients' baseline decisional needs and/or their decision-making process; and e) the effect of coaching or guidance alone. Furthermore, when decision coaching is provided by healthcare professionals within a clinical setting, can its delivery be spread out among different members of the interprofessional team, or does one member of the team need to take responsibility for this role? Another area requiring further evaluation is the use of decision coaching in patients with chronic conditions in which the decision situation is revisited over time and/or there is a series of different decisions to be made [68].

\section{Limitations}

There are two main limitations to consider for this review. First, we did not systematically review the literature for theoretical work related to both concepts; rather we expanded the original theoretical rationale to include literature identified by the research team. Second, the effectiveness of coaching and guidance was limited to a sub-analysis of existing systematic reviews and, therefore, we did not synthesize the literature on the effect of coaching or guidance alone.

\section{Conclusions}

Although there is theoretical evidence to support inclusion of coaching and guidance with PtDAs, there are few randomized controlled trials that have evaluated the effectiveness of coaching used alongside PtDAs and no trials that have evaluated the effectiveness of guidance. Findings may be used by researchers who are developing 
or evaluating PtDAs and by key stakeholders who are involved in implementing PtDAs within routine practice.

\section{List of abbreviations used}

FAST: Formulate issues, Analyze issues, Synthesize insights, Translate; IP-SDM Model: Interprofessional Shared Decision Making Model; PtD̄As: patient decision aids

\section{Competing interests}

Jeff Belkora has received funding for partial salary support since 2004 and Jennifer Kryworuchko received a doctoral fellowship award from the Informed Medical Decisions Foundation, a not-for-profit (501 (c)3 ) private foundation (http://www.informedmedicaldecisions.org). The Foundation develops content for patient education programs. The Foundation has an arrangement with a for-profit company, Health Dialog, to co-produce these programs. The programs are used as part of the decision support and disease management services Health Dialog provides to consumers through health care organizations and employers.

Dawn Stacey, Karen Eden, Mirjam Korner, France Legare, Marie-Chantal Loiselle, Aubri Hoffman, Joyce Davison, Mary Anne Durand, and Richard Street have nothing to declare.

\section{Authors' contributions}

DS led the group's work on the update process. JK helped to draft the manuscript. All authors participated in the review process, provided content expertise, and read and approved the final manuscript.

\section{Declarations}

Publication of this supplement was funded by an unrestricted grant from the Informed Medical Decisions Foundation and by the University Research Chair in Knowledge Translation to Patients, University of Ottawa, Canada. Administrative and editorial support for this supplement was provided by The University of Texas MD Anderson Cancer Center.

This article has been published as part of BMC Medical Informatics and Decision Making Volume 13 Supplement 2, 2013: The International Patient Decision Aid Standards (IPDAS) Collaboration's Quality Dimensions: Theoretical Rationales, Current Evidence, and Emerging Issues. The full contents of the supplement are available online at http://www. biomedcentral.com/bmcmedinformdecismak/supplements/13/S2.

\section{Authors' details}

'School of Nursing, University of Ottawa and Clinical Epidemiology Program, Ottawa Hospital Research Institute, 451 Smyth Road (RGN Room 1118), Ottawa, Ontario, K1H 8M5, Canada. ${ }^{2}$ College of Nursing, University of Saskatchewan, 107 Wiggins Road, Saskatoon, Saskatchewan S7N 5E5, Canada. ${ }^{3}$ Institute for Health Policy Studies, University of California, San Francisco, 3333 California Street, Suite 265, San Francisco, California 94118, USA. ${ }^{4}$ College of Nursing, University of Saskatchewan, 107 Wiggins Road, Saskatoon, Saskatchewan S7N 5E5, Canada. ${ }^{5}$ Department of Psychology, School of Life and Medical Sciences, University of Hertfordshire, College Lane Campus, Hatfield, AL 109AB, UK. ${ }^{6}$ Department of Medical Informatics and Clinical Epidemiology, Oregon Health and Science University, 3181 SW Sam Jackson Park Road, Portland, Oregon 97239-3098, USA. 7 The Dartmouth Institute for Health Policy and Clinical Practice, Geisel School of Medicine at Dartmouth College, 46 Centerra Parkway (HB7250), Lebanon, New Hampshire 03766, USA. ${ }^{8}$ Department of Medical Psychology and Medical Sociology, University of Freiburg, Hebelstr. 29, 79104 Freiburg, Germany. ${ }^{9}$ Department of Family Medicine and Emergency Medicine, Université Laval, Pavillon Ferdinand-Vandry, 1050, avenue de la Médecine, Local 4617, Quebec, Province of Quebec G1V 0A6, Canada. ${ }^{10}$ School of Nursing, Faculty of Medicine and Health Sciences, University of Sherbrooke, 150, place Charles-Le Moyne (Bureau 200), Longueuil, Province of Quebec J4K 0A8, Canada. "'Department of Communication, Texas A\&M University, College Station, Texas 77843-4234, USA.

Published: 29 November 2013

\section{References}

1. Elwyn G, O'Connor A, Stacey D, Volk R, Edwards A, Coulter A, the International Patient Decision Aid Standards (IPDAS) Collaboration:
Developing a quality criteria framework for patient decision aids: online international Delphi consensus process. BMJ 2006, 333:417-422.

2. O'Connor AM, Elwyn G, Stacey D, IPDAS Collaboration: International Patient Decision Aid Standards (IPDAS) Collaboration Background Voting Document. 2004 [http://www.ohri.ca/decisionaid].

3. Stacey D, Murray MA, Légaré F, Dunn S, Menard P, O'Connor A: Decision coaching to support shared decision making: A framework, evidence, and implications for nursing practice, education, and policy. Worldviews Evid Based Nurs 2008, 5:25-35.

4. Stacey D, Kryworuchko J, Bennett C, Murray MA, Mullan S, Légaré F: Decision coaching to prepare patients for making health decisions: A systematic review of decision coaching in trials of patient decision aids. Med Decis Making 2012, 32:E22-33.

5. Durand MA, Stiel M, Boivin J, Elwyn G: Where is the theory? Evaluating the theoretical frameworks described in decision support technologies. Patient Educ Counsel 2008, 71:125-35.

6. Sepucha KR, Fowler FJ, Mulley AG: Policy support for patient-centered care: The need for measurable improvements in decision quality. Health Aff 2004

7. Ratliff A, Angell M, Dow R, Kupperman M, Nease R, Fisher R, Fischer ES, Redelmeier DA, Faughnan ME, Rimer BK, Pauker SP, Pauker SG, Sox HC: What is a good decision? Eff Clin Pract 1999, 2:185-197.

8. Fishburn P: Normative theories of decision making under risk and under uncertainty. In Decision making: Descriptive, normative and prescriptive interactions. New York, NY: Cambridge University Press:Bell D, Raiffa H, Tversky A 1988:78-98.

9. Howard RA, Matheson JE: The principles and applications of decision analysis. Menlo Park: Strategic Decision Group; 1989

10. Russo E: Decision traps. Top ten barriers to brilliant decision-making and how to overcome them. New York, NY: Fireside Publisher; 1990.

11. Charles C, Gafni A, Whelan T: Shared decision-making in the medical encounter: what does it mean? (or it takes at least two to tango). Soc Sci Med 1997, 44:681-692.

12. Makoul G, Clayman ML: An integrative model of shared decision making in medical encounters. Patient Educ Counsel 2006, 60:301-312

13. Tamblyn R, Abrahamowicz M, Dauphinee D, Wenghofer E, Jacques A, Klass D, Smee S, Blackmore D, Winslade N, Girard N, Du Berger R, Bartman I, Buckeridge DL, Hanley JA: Physician scores on a national clinical skills examination as predictors of complaints to medical regulatory authorities. JAMA 2007, 298:993-1001.

14. Hack TF, Degner LF, Parker PA: The communication goals and needs of cancer patients: A review. Psycho-Oncology 2005, 14:831-845.

15. Kiesler DJ, Auerbach SM: Optimal matches of patient preferences for information, decision-making and interpersonal behaviour: Evidence, models and interventions. Patient Educ Counsel 2006, 61:319-341.

16. Donnelley W. Why SOAP is bad for the medical record. Arch Intern Med 1992, 152:481-484

17. Knowles MS, Holton E, Swanson RA: The adult learner: The definitive classic in adult education and human resource development. Houston, Texas: Gulf Publishing Company; 51998.

18. Knowles MS: The adult learner: A neglected species. Houston, Texas: Gulf Publishing Company; 41990.

19. Mezirow J: Fostering critical reflection in adulthood: A guide to transformative and emancipatory learning. San Francisco, California: Jossey-Bass Publishers; 1990.

20. Bandura A: Self-efficacy mechanism in human agency. Am Psychol 1982, 37:122-147.

21. Krueter M, Ricardo W: Tailored and targeted health communication: Strategies for enhancing information relevance. Am J Health Behav 2003, 27:S227-S232.

22. Witt J, Elwyn G, Wood F, Brain K: Decision making and coping in healthcare: The coping in deliberation (CODE) framework. Patient Educ Counsel 2012, 88:256-261

23. Blom KA, Montgomery H: Perspectives and emotions in personal decision making. In Decision making cognitive models and explanations. London, UK: Routledge:Ranyard R, Crozier WR, Svenson O 1997:72-89.

24. O'Connor AM: Validation of a Decisional Conflict Scale. Med Decis Making 1995, 15:25-30

25. Bekker HL, Legaré F, Stacey D, O'Connor AM, Lemyre L: Is anxiety a suitable measure of decision aid effectiveness: a systematic review? Patient Educ Counsel 2003, 50:255-262. 
26. Belkora J: Promoting critical reflection in breast cancer decision making. In Shared decision-making in health care: Achieving evidence-based patient choice. Oxford: Oxford University Press;Edwards A, Elwyn G 2009:297-204.

27. Légaré F, Stacey D, Pouliot S, Gauvin FP, Desroches S, Kryworuchko J, Dunn S, Elwyn G, Frosch D, Gagnon MP, Harrison MB, Pluye P, Graham ID: Interprofessionalism and shared decision-making in primary care: $\mathrm{A}$ stepwise approach towards a new model. J Interprof Care 2011, 25:18-25.

28. Légaré F, Stacey D, Gagnon S, Dunn S, Pluye P, Frosch D, Kryworuchko J, Elwyn G, Gagnon MP, Graham ID: Validating a conceptual model for an interprofessional approach to shared decision making: A mixed methods study. J Eval Clin Pract 2011, 17:554-564.

29. Stacey D, Légaré F, Pouliot S, Kryworuchko J, Dunn S: Shared decision making models to inform an interprofessional perspective on decision making: A theory analysis. Patient Educ Counsel 2010, 80:164-172.

30. Légaré F, Stacey D, Briere N, Fraser K, Desroches S, Dumont S, Sales A, Puma C, Aube D: Healthcare providers' intentions to engage in an interprofessional approach to shared decision making in home care programs: A mixed methods study. J Interprof Care 2013, 1-9.

31. Kryworuchko J, Stacey D, Peterson WE, Heyland DK, Graham ID: A qualitative study of family involvement in decisions about life support in the intensive care unit. Am J Hosp Palliat Medicine 2012, 29:36-46.

32. de Rosenroll A: Perspectives of patients' significant others in dialysis modality decision making. University of Ottawa, Ottawa, Canada; 2011, Master's of Science in Nursing.

33. O'Connor AM, Tugwell P, Wells G, Elmslie T, Jolly E, Hollingworth G: A decision aid for women considering hormone therapy after menopause: Decision support framework and evaluation. Patient Educ Counsel 1998, 33:267-279.

34. Stacey D, O'Connor AM, Graham ID, Pomey MP: Randomized controlled trial of the effectiveness of an intervention to implement evidencebased patient decision support in a nursing call centre. J Telemed Telecare 2006, 12:410-415

35. Stacey D, Chambers SK, Jacobsen MJ, Dunn J: Overcoming barriers to cancer helpline professionals providing decision support for callers" An implementation study. Oncol Nurs Forum 2008, 35:1-9.

36. Murray MA, Stacey D, Wilson KG, O'Connor AM: Skills training to support patients considering location of end-of-life care: A randomized control trial. J Palliat Care 2010, 26:112-121.

37. Belkora J, Loth MK, Chen DF, Chen JY, Volz S, Esserman LJ: Monitoring the implementation of Consultation Planning, Recording, and Summarizing in a breast care centre. Patient Educ Counsel 2008, 73:536-543.

38. Belkora J, Loth MK, Volz S, Rugo HS: Implementing decision and communication aids to facilitate patient-centred care in breast cancer: A case study. Patient Educ Counsel 2009, 77:360-368.

39. Belkora JK, Teng A, Volz S, Loth MK, Esserman LJ: Expanding the reach of decision and communication aids in a breast care center: A quality improvement study. Patient Educ Counsel 2010, 83:234-239.

40. Hacking B, Wallace LM, Scott S, Kosmala-Anderson J, Belkora J, McNeill A: Decision navigation intervention for early stage prostate cancer patients in Scotland - A randomised controlled trial. Psycho-Oncology 2012, epub May 9.

41. Belkora J, Stupar L, O'Donnell S, Loucks A, Moore D, Jupiter C, Johnson N, Wilson L: Decision support by telephone: Randomized controlled trial in a rural community setting. Patient Educ Counsel 2012, 89:134-142.

42. O'Connor AM: Ottawa Decision Support Framework to address decisional conflict. 2006 [http://decisionaid.ohri.ca/odsf.html].

43. Stacey D, Bennett CL, Barry MJ, Col NF, Eden KB, Holmes-Rovner M, Llewellyn-Thomas $H$, Lyddiatt A, Légaré $F$, Thomson R: Decision aids for people facing health treatment or screening decisions. Cochrane Database Syst Rev 2011, 1-208.

44. Légaré $F$, Politi $M$, Drolet $R$, Desroches $S$, Stacey D, Bekker $H$, the SDM-CPD Team: Training health professionals in shared decision making: An international environmental scan. Patient Educ Counsel 2012, 88:159-169.

45. Bekker HL, Hewison J, Thornton JG: Applying decision analysis to facilitate informed decision making about prenatal diagnosis for Down syndrome: a randomised controlled trial. Prenatal Diagnosis 2004, 24:265-275.

46. Green MJ, Peterson SK, Baker MW, Harper GR, Friedman LC, Rubinstein WS, Mauger DT: Effect of a computer-based decision aid on knowledge, perceptions, and intentions about genetic testing for breast cancer susceptibility: A randomized controlled trial. JAMA 2004, 292:442-452.
47. Lalonde L, O'Connor AM, Duguay P, Brassard J, Drake E, Grover SA: Evaluation of a decision aid and a personal risk profile in community pharmacy for patients considering options to improve cardiovascular health: the OPTIONS pilot study. Int J Pharm Pract 2006, 14:51-62.

48. Miller SM, Fleisher L, Roussi P, Buzaglo JS, Schnoll R, Slater E, Raysor S, Popa-Mabe M: Facilitating informed decision making about breast cancer risk and genetic counseling among women calling the $\mathrm{NCl}^{\prime}$ ' Cancer Information Service. Journal of Health Communication 2005, 10:119-136.

49. Solberg LI, Asche SE, Sepucha K, Thygeson NM, Madden JE, Morrissey L, Kraemer KK, Anderson LH: Informed choice assistance for women making uterine fibroid treatment decisions: A practical clinical trial. Med Decis Making 2010, 30:444-452

50. Wolf AM, Nasser JF, Schorling JB: The impact of informed consent on patient interest in prostate-specific antigen screening. Arch Intern Med 1996, 156:1333-1336

51. Wolf AMD, Schorling JB: Does informed consent alter elderly patients preferences for colorectal cancer screening? J Gen Intern Med 2000, 15:24-30.

52. Fraenkel $L$, Rabidou N, Wittink D, Fried T: Improving informed decisionmaking for patients with knee pain. J Rheumatol 2007, 34:1894-1898

53. Jones LA, Weymiller AJ, Shah N, Bryant SC, Christianson TJH, Guyatt GH, Gafni A, Smith SA, Montori VM: Should clinicians deliver decision aids? Further exploration of the statin choice randomized trial results. Med Decis Making 2009, 29:468-474.

54. Griffin SJ, Kinmonth AL, Veltman MW, Gillard S, Grant J, Stewart M: Effect on health-related outcomes of interventions to alter the interaction between patients and practitioners: A systematic review of trials. Ann Fam Med 2004, 2:595-608.

55. Harrington J, Noble LM, Newman SP: Improving patients' communication with doctors: A systematic review of intervention studies. Patient Educ Counsel.

56. Wennberg DE, Marr A, Lang L, O'Malley S, Bennett G: A randomized trial of a telephone care-management strategy. NEJM 2010, 363:1245-1255.

57. Greenfield S, Kaplan S, Ware JE Jr.: Expanding patient involvement in care. Effects on patient outcomes. Ann Intern Med 1985, 102:520-528.

58. Greenfield S, Kaplan SH, Ware JE Jr., Yano EM, Frank HJ: Patients' participation in medical care: effects on blood sugar control and quality of life in diabetes. J Gen Intern Med 1988, 3:448-457.

59. Roter D: Doctors talking with patients/patients talking with doctors: Improving communication in medical visits. Westport, CT: Auburn House; 1993

60. Bennett AEE: Communication between doctors and patients. Oxford, UK Oxford University Press; 1976.

61. Bensing JM, Dronkers J: Instrumental and affective aspects of physician behavior. Med Care 1992, 39:283-298.

62. Cegala DJ, Socha McGee D, McNeilis KS: Components of patients' and doctors' perceptions of communication competence during a primary care medical interview. Health Commun 1996, 8:1-27.

63. O'Connor AM, Stacey D, Légaré F: Coaching to support patients in making decisions. BMJ 2008, 336:228-229.

64. Woolf SH, Chan ECY, Harris R, Sheridan SL, Braddock CH, Kaplan RM, Krist A, $\mathrm{O}^{\prime}$ Connor AM, Tunis S: Promoting informed choice: Transforming health care to dispense knowledge for decision making. Ann Intern Med 2005, 143:293-300.

65. Patient Decision Aids Research Group, Ottawa Hospital Research Institute: A to Z Inventory of Decision Aids. 2013 [http://www.ohri.ca/decisionaid].

66. Stacey D, Hawker G, Dervin G, Tomek I, Cochran N, Tugwell P, $\mathrm{O}^{\prime}$ Connor AM: Improving shared decision making in osteoarthritis. BMJ 2008, 336:954-955.

67. Stacey D, Graham ID, O'Connor AM, Pomey MP: Barriers and facilitators influencing call centre nurses' decision support for callers facing valuessensitive decisions: A mixed methods study. Worldviews on Evid Based Nurs 2005, 2:184-195.

68. Montori VM, Gafni A, Charles C: A shared treatment decision-making approach between patients with chronic conditions and their clinicians: the case of diabetes. Health Expect 2006, 9:25-36.

69. Hamann J, Langer B, Winkler V, Busch R, Cohen R, Leucht S, Kissling W: Shared decision making for in-patients with schizophrenia. Acta Psychiat Scand 2006, 114:265-273.

70. Lerman C, Biesecker BB, Benkendorf JL, Kemer J, Gomez-Caminero A, Hughes $C$, Reed MM: Controlled trial of pretest education approaches to 
enhance informed decision-making for BRCA1 gene testing. J Nat/ Cancer Inst 1997, 89:148-157.

71. van Peperstraten A, Nelen W, Grol R, Zielhuis G, Adang E, Stalmeier P, Hermens R, Kremer J: The effect of a multifaceted empowerment strategy on decision making about the number of embryos transferred in invitro fertilisation: Randomised controlled trial. BMJ 2010, 340:1-8.

72. Kennedy A, Sculpher MJ, Coulter A, Dwyer N, Rees M, Abrams KR, Horsley S, Cowley D, Kidson C, Kirwin C, Naish C, Stirrat G: Effects of decision aids for menorrhagia on treatment choices, health outcomes, and costs. A randomized controlled trial. J Am Med Assoc 2002, 288:2701-2708.

73. Vodermaier A, Caspari C, Koehm J, Kahlert S, Ditsch N, Untch M: Contextual factors in shared decision making: a randomised controlled trial in women with a strong suspicion of breast cancer. Brit J Cancer 2009, 100:590-597.

74. Rothert ML, Holmes-Rovner M, Rovner D, Kroll J, Breer L, Talarczyk G, Schmitt N, Padonu G, Wills C: An educational intervention as decision support for menopausal women. Res Nurs Health 1997, 20:377-387.

75. Deschamps MA, Taylor JG, Neubauer SL, Whiting S, Green K: Impact of pharmacist consultation versus a decision aid on decision making regarding hormone replacement therapy. Int J Pharm Pract 2004, 12:21-28.

76. Green MJ, Biesecker BB, Mclnerney AM, Mauger D, Fost N: An interactive computer program can effectively educate patients about genetic testing for breast cancer susceptibility. Am J Med Genet 2001, 103:16-23.

77. Hunter AGW, Cappelli M, Humphreys L, Allanson JE, Chiu TT, Peeters C, Moher D, Zimak A: A randomized trial comparing alternative approaches to prenatal diagnosis counseling in advanced maternal age patients. Clin Genet 2005, 67:303-313

78. Davison BJ, Degner L: Empowerment of men newly diagnosed with prostate cancer. Cancer Nurs 1997, 20:187-196.

79. Myers RE, Daskalakis C, Cocroft J, Kunkel EJS, Delmoor E, Liberatore M, Nydick RL, Brown ER, Gay RN, Powell T, Powell RL: Preparing AfricanAmerican men in community primary care practices to decide whether or not to have prostate cancer screening. I Natl Med Assoc 2005, 97:1143-1154

doi:10.1186/1472-6947-13-S2-S11

Cite this article as: Stacey et al: Coaching and guidance with patient decision aids: A review of theoretical and empirical evidence. $B M C$ Medical Informatics and Decision Making 2013 13(Suppl 2):S11.

\section{Submit your next manuscript to BioMed Central and take full advantage of:}

- Convenient online submission

- Thorough peer review

- No space constraints or color figure charges

- Immediate publication on acceptance

- Inclusion in PubMed, CAS, Scopus and Google Scholar

- Research which is freely available for redistribution

Submit your manuscript at www.biomedcentral.com/submit
Biomed Central 